\title{
Knowledge infrastructures and the inscrutability of openness in education
}

\section{Richard Edwards}

To cite this article: Richard Edwards (2015) Knowledge infrastructures and the inscrutability of openness in education, Learning, Media and Technology, 40:3, 251-264, DOI:

10.1080/17439884.2015.1006131

To link to this article: http://dx.doi.org/10.1080/17439884.2015.1006131 (c) 2015 The Author. Published by Taylor \&
Francis.

曲 Published online: 03 Feb 2015.

Submit your article to this journal $\pi$

Џ Article views: 670

Q View related articles $\sqsubset$

View Crossmark data 


\title{
Knowledge infrastructures and the inscrutability of openness in education
}

\author{
Richard Edwards* \\ School of Education, University of Stirling, Stirling, UK \\ (Received 25 July 2014; accepted 5 January 2015)
}

\begin{abstract}
Openness has a long genealogy in education. Whether through the use of post, radio, television and digital technologies, extending learning opportunities to more and a wider range of people has been a significant aspect of educational history. Transcending barriers to learning has been promoted as the means of opening educational opportunities in highly normative ways, focusing on the media through which to remove the limits of institutional selection, and of space and time. While there is an obvious attractiveness is such notions, they do little to engage with the critical research on the selectiveness and exclusions inherent in all curricula and pedagogic approaches, however open. The nature, scale and range of digital technologies have seen resurgent interest in the possibilities of openness in education. However, these technologies work on the basis of ontologies, code, algorithms and standards to build knowledge infrastructures that are not always open or opening. This article will suggest that the work of the knowledge infrastructures of open education results in an inherent inscrutability within its practices, which is elusive in terms of significance, processes and effects.
\end{abstract}

Keywords: digital technologies; openness; knowledge infrastructures; code; algorithms

\section{Introduction}

Openness has a long, if sometimes overlooked, genealogy in education. Whether through public libraries and museums, through the use of post, radio and television and, more recently, through the use of digital technologies, extending learning opportunities to more people and a wider range of people has been a significant aspect of educational history and development. Transcending 'barriers to learning' has been promoted as the means of extending educational opportunities in highly normative ways, focusing on the media through which to remove the identified limits of institutional selection, space/time and

\footnotetext{
*Email r.g.edwards@stir.ac.uk 
resources. With the growth of the possibilities promoted through the development of digital technologies, the internet and World Wide Web, openness has taken new and different forms with particular initiatives and emphasis in recent years being given to the promotion of Open Educational Resources (OERs) and Massive Open Online Courses (MOOCs).

Extensive positive claims are made for extending the openness of educational opportunities, including their capacity to overcome barriers to access to education, and to provide opportunities for people distributed by geography and income to become connected to learning. Integral to these educational endeavours is the extension of electricity and bandwidth. Extending openness is situated within broader trends towards positively affirming lifelong learning, reducing the monopoly of educational institutions on learning and providing greater opportunities for peer learning and the co-production of knowledge. While there is a surface normative attractiveness in such notions, they do little to engage with the critical research on such issues as access to the necessary hardware, software and bandwidth to be able to access such opportunities, the work of the digital on the forms of data, information and knowledge opened, the worthwhileness of the resources and courses that are opened given not all education is good education, what is learnt rather than what is available, issues of expertise and authority in knowledge production, and the value to participants in relation to their own goals and aspirations. Nor do they engage with those who view closed educational spaces as important for nurturing opportunities to learn away from others, a view propounded by, for instance, some feminists.

While some (Camilleri, Ehlers, and Pawlowski 2014) see such issues as questions of quality to be addressed in extending openness as a normative goal, others offer a more critically evaluative approach. For instance, Bayne and Ross (2014) provide a useful review of these issues in relation to MOOCs, but many of these are arguably generic to all initiatives to openness in education through the use of the internet and World Wide Web. Similarly, Knox's (2013) critique of the OERs' movement raises many issues that are inherent in any claims to openness in education. Meanwhile, Panke and Seufert (2013) raise important questions in relation to the precise forms of openness associated with OERs, and the different learning theories that can be drawn upon to frame what constitutes the educational in making resources digitally available through such means. Much of the impetus behind such reviews and critiques seeks to transcend the limitations of existing forms of open education, presumably to extend openness even further.

While important, most of these issues are not the focus of this article. It does, however, pick up on Knox's (2013) argument that openness is under-theorized, although eschewing his use of Berlin's concepts to liberty as an adequate base for such theorizing. By contrast, this article takes as its starting point the selectiveness and exclusions inherent in all, however different, curricula and pedagogic approaches, including those developed within a discourse of openness. 
Theoretically, it starts from the assumption that openness is not the opposite of closed-ness, nor is there simply a continuum between the two. The theoretical position adopted here is that all forms of openness entail forms of closed-ness and that it is only through certain closings that certain openings become possible and vice versa. Different educational practices involve, therefore, the interplay of openness and closed-ness which can be examined empirically. This is the case for all practices, whether face-to-face or digital. Initiatives to open education through the use of digital technologies therefore reconfigure rather than simply overcome the interplay of open-closed-ness. This is not to say that these initiatives cannot be beneficial, but they will be selectively so, as is the case with all educational practices. To enable students to learn in geographically distributed spaces and times does open educational possibilities, but there are certain closures associated with this, such as the possibilities for physical interactions. An important question therefore becomes not simply whether education is more or less open, but what forms of openness are worthwhile and for whom; openness alone is not an educational virtue.

Important actors in this interplay of openness-closed-ness, but ones that have yet to be fully explored, are the knowledge infrastructures enacted through digital technologies that increasingly are integral to open educational initiatives. The impact of the digital on knowledge infrastructures and the issues they raise has become a matter of major concern for researchers across a range of disciplines (Kitchin and Dodge 2011; Edwards et al. 2013), yet this is not always reflected adequately in debates about openness in education. While the nature, scale and range of internet-based technologies have seen resurgent interest in the possibilities of open education, these work on the basis of ontologies, code, algorithms and standards in order to enact opportunities in particular ways. How and what is opened is not only about the intentions of designers and the resources available, but also the work done by the knowledge infrastructures themselves. This is something which is not always visible and entails closures as well as openings.

This work has been argued previously as part of the hidden curricula of digital technologies in education (Edwards and Carmichael 2012). This notion of the hidden suggests that, once discovered, this work can be unveiled and made open, which is part of the logic of transcendence mentioned earlier. However, some of the research on the inscrutability of the ontologies, code, algorithms and standards within knowledge infrastructures suggests that there is an inherent elusiveness and mystery at play arising from 'machine-driven processing of data at a scale and pace beyond immediate human capabilities' (Halford, Pope, and Weal 2012, 179). When examining open education initiatives therefore, we may be facing not only the interplay of openness and closedness, but also an emerging inscrutability in the work of the knowledge infrastructures in what is being enacted.

This article, therefore, is a theoretically informed exploration of openness in the knowledge infrastructures of open education enacted through digital 
technologies. It draws from a range of theoretical and empirical studies in a number of disciplines to highlight the need for educational research to be located within the concerns and approaches of the wider social sciences. The article is in three parts. First, I shall outline in more detail the historical discussion of openness in education and the argument that open educational initiatives do not simply open but also close at the same time. This suggests that framing educational initiatives as simply expanding openness do not do justice to the complexities of the practices in play. Second, I shall argue that one aspect of this complexity is the work of digital technologies in the knowledge infrastructures in open educational initiatives and that this work is becoming and more inscrutable. This adds to the complexity of engaging with the play of openand closed-ness in relation to such initiatives, as inscrutability implies an uncertainty that cannot be resolved. Finally, I shall draw out some issues in relation particularly to trying to research the work of digital technologies in the knowledge infrastructures of open education.

\section{Opening-closing}

Research into the characteristics and significance of open education burgeoned following the development of open universities in a number of countries from the 1960s. Many developments since have sought to extend openness in different ways, both as part of formal educational provision and as part of more general media and cultural life. Early identification of the aspects of openness - in relation to, for instance, time, space, pace, enrolment and prior experience (Lewis 1993) - was often used to offer critiques of the extent to which educational opportunities had been opened. To be more rather than less open was a normative goal for such initiatives and open universities in particular were often contrasted positively with the closed cloistered environments of more traditional institutions. However, there was also the recognition that educational provision could not be completely open in all its aspects (Paul 1993) for practical, economic and educational reasons.

While debates emerged on the characteristics of open education, there was also research on the significance of such trends. Some (Evans and Nation 1992; Edwards 1993) argued that open education was linked to wider economic and societal shifts to create more flexible labour markets and workplaces, wherein initial education was no longer adequate to sustain employment across the life course. Here, open education was positioned as more flexible and therefore better able to meet the lifelong economic and labour market demands of post-Fordist production techniques and postmodern cultural conditions. Others (Field 1996) argued that open learning was entangled in the emergence of consumer culture and could better be understood within the theoretical framing of discourses of consumption rather than more traditional discourses of education. Here, open learning provided enhanced opportunities for the accumulation of cultural capital. 
It was the influence of poststructuralism and postmodernism (Usher and Edwards 1994; Stronach and MacLure 1997) that shifted the discussion of openness and closed-ness from a continuum to a binary, thereby raising questions about any inherent worthwhileness in the open. It is not a new insight to suggest that much educational debate is structured by such binaries - openclosed, free-paid for, inclusion-exclusion and visible-hidden - within which there is a normative bias towards the former over the latter. While normatively and practically powerful, binaries such as open-closed and the visible-hidden are capable of deconstruction, as demonstrated powerfully in some of the work of Derrida $(1981,1998)$. Derrida argues that to open a space is to deny the other spaces that make that opening possible. The space opened depends upon the spaces that are closed by the opening. Or, as Bowker $(2014,1793)$ puts it in relation to knowledge infrastructures,

every act of admitting data into the archive is simultaneously an act of occluding other ways of being, other realities. The archive cannot in principle contain the world in small; its very finitude means that most slices of reality are not represented. The question for theory is what the forms of exclusion are and how we can generalize about them.

In other words, whether in an archive, a curriculum, or any educational resource, there is a selection and occlusion of other possibilities inherent in the very practices of their enactment. Digital technologies do not overcome occlusion, but reconfigure its possibilities.

Derrida points to the paradoxical and relational dimensions of language, to the dependence for meaning upon the Other, that which is denied. As Natter and Jones $(1997,146)$, summarizing Derrida, put it, "the outside of any category is already found to be resident within, permeating the category from the inside through its traceable presence-in-absence within the category'. In other words, terms only mean something in relation to other terms, about which they can be silent; and exercises of power are inscribed in such practices. This is also the case in relation to the selection of data in relation to an archive or, in education, a curriculum. Opening education through specific practices therefore requires closures which can be silenced and hidden. When researching openness in education therefore, at the same time, we also need to explore the closures and silences that make the specific practices of openness possible.

In taking the perspective derived from Derrida, the task for educational researchers becomes one of engaging in a struggle over the specific approaches to open-closed-ness rather than pursuing openness per se as a worthwhile educational goal. The question is not whether to make education more open, but what forms of openness and closed-ness are justifiable. To bring to the fore the paradoxical inter-relationship of open-closed-ness is to investigate the micro-practices of education and their powerful effects, the specific forms 
they take and the possibilities for alternative practices. It is to deconstruct openness as an inherently worthwhile educational goal and bring to the fore explicit questions about the basis upon what specific forms of selectivity and closure are justifiable in particular educational practices, however open.

As I have indicated, the assumption tends to be that it is a good thing that everyone should have as much access to education as possible, and this puts to one side questions of what is worthwhile and for whom; questions traditionally discussed in relation to the selections of curricula and pedagogy. Popular educational discourses, therefore, have become concerned more with opening education and ensuring its quality, rather than focusing on the grounds for selecting particular curricula and pedagogy for specific educational purposes (Camilleri, Ehlers, and Pawlowski 2014). This is a serious limitation on educational research. In drawing upon Derrida, we are pointed to the closures and occlusions of open education. One aspect of this to which I now wish to turn is the work of digital technologies in the knowledge infrastructures of education.

\section{Knowledge infrastructures in opening education}

Edwards (2010) refers to knowledge infrastructures as the 'robust networks of people, artifacts, and institutions that generate, share and maintain specific knowledge about the human and natural worlds'. Knowledge infrastructures are

ecologies, or complex adaptive systems; they consist of numerous systems, each with unique origins and goals, which are made to interoperate by means of standards, socket layers, social practices, norms, and individual behaviours that smooth out the connections among them. (Edwards et al. 2013, 5)

MOOCs and OERs may be both examples of such knowledge infrastructures and also rely upon them. Both the development of such infrastructures and their effects raise important questions for education, both in terms of their openness and the significance of their openness. We can think of all education as forms of knowledge infrastructures, but for this article, I am particularly concerned with the work of the digital in the enactments of open education.

However, for many, perhaps most, educators, computers simply work, and the rhetoric of hardware, operating systems and software is that of, for instance, access to new resources, innovations in teaching and learning, the extension of reach, and, of course, greater openness. Over time, there has developed a powerful discourse which encourages practitioners to view digital technology in education, as elsewhere in daily life, as seamless and unremarkable (Thrift 2004; Kitchin and Dodge 2011) and to be taken for granted. More generally, the 'tool' tends to be the dominant metaphor for thinking about digital technology in education. Edwards and Carmichael (2012) argue that examining the use of digital technology in education as an aspect of the hidden curriculum opens 
up for more explicit scrutiny those aspects of curriculum and pedagogy wherein technologies are naturalized and considered as simply tools by which education is 'delivered'. Questions of purpose and power in education are reduced to questions of technical delivery. In particular, they argue that the effects of developing standards, code and algorithms on the representation of data, the forms of teaching and learning that are possible, and the notion of the student assumed and enacted, were part of a 'secret code' of the hidden curriculum (see also Loveless and Williamson 2013), or, more widely, what is said to be part of what Thrift (2004) has termed a 'technological unconscious' of contemporary life. In other words, we cannot take the information and representations with which we interact through digital means for granted, given the work of software and hardware, and the automated work that goes on 'behind the screen'.

Exploring the work of software as an aspect of the hidden curriculum has been a surprisingly small part of the research on openness in education to date. However, recent developments in digital technology and growing research on the work of code and algorithms (Barocas, Hood, and Ziewitz 2013; Manovich 2013) and knowledge infrastructures (Halford, Pope, and Weal 2012; Edwards et al. 2013) in daily life more generally have the potential for providing significant resources through which to explore the embedded work of software in the play of open-closed-ness in education. This research points us towards giving attention to the knowledge infrastructures, software and associated practices through which digital education is enacted. Knowledge infrastructures do not simply represent data. They select, translate and transform them. It is the ontologies, codes, algorithms and the linking of data, the applications of technical standards, and ways in which decision-making and reasoning are articulated in computer software that (along with the hardware and the electronic infrastructures of networks) make things (such as search engines, web applications and databases) perform in ways and become specific actors in particular educational practices.

In relation to this, I shall here focus on the largely unrecognized role played by forms of classification and standardization associated with the development of digital databases, and the ways in which complex knowledge is represented (Lampland and Star 2009). To classify and standardize requires the removal of ambiguity from representation, when of course many knowledge claims are ambiguous and contested. While, as Bowker $(2005,140)$ argues, 'you can't store data without a classification system', in education how this occurs and with what effects, is largely left unexamined, unquestioned and hidden from those using the technology. Yet, it is fundamental to what is opened and closed through specific digital enactments. Edwards et al. $(2013,10)$ argue that digitalization of data has three main issues with which it is associated:

first, a plethora of 'dirty' data, whose quality may be impossible for other investigators to evaluate; second, weak or non-existent guarantees of long-term 
persistence for many data sources; and finally, inconsistent metadata practices that may render reuse of data impossible - despite their intent to do the opposite.

In similar vein, Halford, Pope, and Weal (2012) explore the implications of the development of the semantic web and the promises propounded about the internet as less a library of documents and more a linked database; the promise of open access to data. The big promises of open data are related in terms of transparency, transcending knowledge silos and the potential to make greater advances in knowledge. These are not unimportant, as the synthesizing of some research in medicine is starting to demonstrate. However, they also point to some of the challenges associated with such promises, not least, the naming of data entities, the structuring of data and the processing of data. To name and categorize an entity in a consistent way across space and time is not without its challenges, not least because such categories themselves might be subject to challenge and change arising from research. These challenges are commonly identified by those who research knowledge infrastructures as well as those who focus more specifically on software. As a result, Halford, Pope, and Weal (2012, 178-179) argue that in the development such infrastructures "making some things "known" tends to obscure other things and, indeed, ways of knowing' and that 'ontology building is not a simple or solely technical matter'.

In this respect, ontology building, the naming and structuring of digital data in the enactment of knowledge infrastructures, has itself become a subject of increasing research in recent years.

Ontologies are an information technology for representing specialized knowledge in order to facilitate communication across disciplines, share data or enable collaboration. In a nutshell, they describe the sets of entities that make up the worldin-a-computer, and circumscribe the sets of relationships they can have with each other. They are a complex and ambitious technical approach to address the problem of diverse languages, heterogeneous categorizations and varied methods for organizing information. In the wake of ontologies the information of a domain is substantially reorganized, facilitating data exchange and reuse. (Ribes and Bowker 2009, 199)

Ontologies are fundamental to the work of digital technologies in knowledge infrastructures, but how they are developed and the extent to which that process is taken for granted once they are developed are critically important in relation to the digital representation of knowledge in open education. In their study of the development of an ontology, Ribes and Bowker (2009, 210) found that for those scientists involved 'the primary orientation ... was to complete a working ontology rather than a coming to a definitive resolution'. This was because the outcome was determined by the pragmatic digital requirements for the data to be machine readable. Thus, it is arguable that the representation of data for the purposes of digitalization required different qualities from 
those associated with existing practices in research and pedagogy. In this process, one critical dimension was not achieved in practice - the representation of disagreements, uncertainties, ambiguities and ambivalences. These are qualities that, it might be argued, are critically important to a worthwhile education, but, as we have seen, are problematic to the practices of standardization and categorization integral to the digitization of data.

The scientists involved in Ribes and Bowker's study became 'lay ontologists', but for those involved in using rather than developing the ontology, the decisions necessary to enable the information to be machine readable and the closures associated with this, might be said to be hidden. These practices of inclusion and exclusion in developing ontologies have been identified in similar studies: 'much time and effort is spent reaching agreement about what should be in a given ontology and what should be left out' (Randall et al. 2011, 221). Thus, it has been argued that in their development, knowledge infrastructures 'not only provide new maps to known territories - they reshape the geography itself' (Edwards et al. 2013, 14). We therefore see how extending openness through digital technologies raises important questions about the politics of knowledge, as 'turning everything into data, and using algorithms to analyze it changes what it means to know something' (Manovich 2013, 337). This stark assessment raises important issues for those educators who might espouse a somewhat simplistic normative view on the value of openness in education; specific knowledge infrastructures embed certain opening-closings and the digital is not a neutral tool for learning, but is an actor in shaping possibilities for education.

Ribes and Bowker $(2009,211)$ also point to the importance of temporality in relation to ontologies: 'as knowledge, terminology or concepts change within the scientific community, a once-accurate ontology could become obsolete'. With the passing of time and the incorporation of such data into new knowledge infrastructures, the pre-history of data, the selections and applications of ontologies and standards, and the application of rules can disappear from view. With the advent of semantic technologies, which allow data to be shared, aggregated and reused across a linked web of databases and applications, any act of classification, any assumption encapsulated in a rule expressed in the code of a program, or any decision to exclude certain results from the scope of a search may have implications far beyond its original setting. These implications represent closures and can remain hidden in nature and impact, of which users may be entirely unaware. As Edwards et al. $(2013,7)$ suggest, 'the presentation of datasets as complete, interchangeable products in readily exchanged formats ... may encourage misinterpretation, over reliance on weak or suspect data sources, and "data arbitrage" based more on availability than quality'. The selections and closing which make data sets open may be lost to view.

This points to the increasing complexity of the work of digital technologies in knowledge infrastructures within education, the tracing of which is and is likely to become ever more complex. In the context of existing debates about 
openness, we might anticipate that tracing such work makes the hidden visible through students 'learning to code'. However, does this oversimplify? What if the unveiling of the work ontologies, code, algorithms and standards in knowledge infrastructures does not or cannot make their work fully visible and transparent? What if, as Manovich (2013) suggests, for instance, reading the code is not as feasible as it is sometimes made out to be? This would have profound implications for the practices and understanding of education, as potentially it undermines empirically the more simplistic discourses of openness.

Such questions arise from the overall research on knowledge infrastructures, but there is a particular angle which I wish to emphasize based upon research on the work of computer algorithms. Barocas, Hood and Ziewitz (2013) point out that algorithms have a history and geography of what they can and cannot do, so they are not stable nor singular units of study or analysis. In line with the wider social scientific research on knowledge infrastructures, therefore, they argue that 'algorithms are invoked as powerful entities that govern, judge, sort, regulate, classify, influence, or otherwise discipline the world' (Barocas, Hood, and Ziewitz 2013, 3). They also point to work that suggests the disciplining of studies into particular subjects, for example, computer science and sociology, places limitations on understanding the work of algorithms. In other words, to learn computer programming, as is currently suggested, would not necessarily result in an understanding of the full impact and significance of the work of algorithms, a point also made by Edwards et al. (2013). Thus, the suggestion is that there is a need to study not only software but also the availabilities and forms of data, the challenges associated with linking these and the practices within which they are enacted and which they make possible. In other words, there is the need for different forms of research to be able to engage with the work of the digital in knowledge infrastructures.

Based upon their analysis, Barocas, Hood, and Ziewitz (2013) suggest that it becomes impossible to research the precise work of algorithms. They argue that algorithms are elusive and almost unresearchable; inscrutable. Here, the work of digital technology is not necessarily hidden - by someone or something - but is unknowable in any transparent or open sense. The performances of software become too complex and dynamic to be 'read'. The work being done across space and time with different software and data sets can be alluded to, but is itself elusive. It cannot be made entirely visible. If this is the case, then digital knowledge infrastructures in education may not be part of a hidden curriculum, as their impact may be more profound. There is the possibility that they bring inherent inscrutability within the curriculum, however open. If this is the case, in unveiling the work of digital technologies in knowledge infrastructures in education, we are bringing out the inscrutability of educational practices rather than making them open and visible. In the interplay of open-closedness, there is unresolvable mystery. And perhaps that is necessary for practices to be educational. As Edwards et al. $(2013,15)$ suggest, in articulating what is 
known, we also need to engage with the 'accidental and systematic means by which non-knowledge is produced and maintained'.

The issue is not whether the work of digital knowledge infrastructures can be made open, but of the multiple inscrutable translations that are incorporated into education through the work of ontologies, codes, algorithms and standards (Millerand and Bowker 2009) and in the practices of enacting the curriculum. This argument poses empirical and theoretical questions for researchers in exploring the work of digital technologies in education and whether there are processes at play that may not be hidden, but may be inscrutable. Further questions arise as to whether this would be the case for all digitalized education or only for that which involves particularly complex interplays of ontologies, code, algorithms and standards, and where the boundary line could be drawn. Furthermore, if in researching inscrutability in relation to digitalized education, the inscrutable might also conceptually offer something to our understanding of the opening of education more broadly, especially given the challenges of making transparent all aspects of such practices and accounting satisfactorily for their multiplicity.

\section{An inscrutable ending?}

Manovich $(2013,338)$ argues that

digital code, digital visualization, GIS, information retrieval, machine learning techniques, constantly increasing speed of processors and decreasing cost of storage, big data analytics technologies, social media, and other parts of the modern techno-social universe introduce new ways of acquiring knowledge, and in the processes redefine what knowledge is.

I have argued that for those interested in opening education, this and the broader practices of knowledge infrastructures result in increasing inscrutability in the curriculum. Any simple notions of openness are therefore a fantasy, although an important or powerful one. Empirically, the development of knowledge infrastructures requires many closings, which may become taken for granted in their educational enactments. However, this is not without its challenges, as tracing the work of software is itself inscrutable. Theoretically, we can draw upon deconstruction to explore the closings that make certain openings possible and vice versa, but methodologically, there are bigger challenges.

For Berry $(2011,4)$, the research challenge raised by the digital is 'to bring software back into visibility so that we can pay attention to both what it is (ontology), where it has come from (through media archaeology and genealogy), but also what it is doing (through a form of mechanology)'. The latter is particularly important in relation to education. However, it does depend upon an assumption that the work of software can indeed be made visible and does not take into account the wider assemblings in knowledge infrastructures. However, the challenges are greater, if the work of digital technologies in 
knowledge infrastructures becomes less traceable and more inscrutable. This is something Berry $(2011,5)$ himself acknowledges; 'looking at computer code is difficult due to its ephemeral nature, the high technical skills required of the researcher and the lack of analytical or methodological tools available'. However, he also argues that a phenomenology of computation can enable researchers to explore 'the ways in which code is able to structure experience in concrete ways' (Berry 2011, 39).

Edwards et al. (2013) suggest a number of high-level strategies for researching the work of the digital in knowledge infrastructures:

- Create and nourish mechanisms for large-scale, long-tern research.

- Build inter-disciplinary collaborations across natural and social sciences.

- Develop comparative analysis techniques for studying large-scale, longterm data.

- Create sustainable, shareable data archives.

- Build better software for qualitative work.

- Integrate qualitative work with statistical techniques and social network analysis.

- Imagine new forms of cyberscholarship.

These may be too high level to be entirely helpful, but they point to some of the significant challenges that perhaps should inform the priorities in furthering research on openness in education. Whether they would result in making the work of knowledge infrastructures more open or more effectively mapping their inscrutabilities is a further question. However, the increasing research on knowledge infrastructures raises important questions for those interested in opening education that need further exploration empirically and conceptually. This article is intended as an opening into this area of work.

\section{Disclosure statement}

No potential conflict of interest was reported by the author.

\section{Funding}

This work was supported by the Economic and Social Research Council [grant number $\mathrm{ES} / \mathrm{L} 001160 / 1]$.

\section{Notes on contributor}

Richard Edwards is Professor of Education at the University of Stirling, Scotland. He has researched and written extensively on different aspects of educational theory and lifelong learning. The foci for his current research are digital education, and citizen science and informal learning. 


\section{References}

Barocas, S., S. Hood, and M. Ziewitz. 2013. “Governing Algorithms: A Provocation Piece." Paper presented at the governing algorithms conference, New York University, May 16-17.

Bayne, S., and J. Ross. 2014. The Pedagogy of the Massive Open Online Course: The UK View. York: HEA.

Berry, D. 2011. The Philosophy of Software: Code and Mediation in the Digital Age. Basingstoke: Palgrave Macmillan.

Bowker, G. 2005. Memory Practices in the Sciences. Cambridge, MA: MIT Press.

Bowker, G. 2014. "The Theory/Data Thing." International Journal of Communication 8 (5): 1795-1799.

Camilleri, A., U. Ehlers, and J. Pawlowski. 2014. State of the Art Review of Quality Issues Related To Open Educational Resources (OER). Luxembourg: Office of the European Union.

Derrida, J. 1981. Positions. Chicago, IL: University of Chicago Press.

Derrida, J. 1998. Archive Fever: A Freudian Impression. Chicago, IL: University of Chicago Press.

Edwards, R. 1993. "The Inevitable Future? Post-Fordism in Work and Learning." In Adult Learners, Education and Training, edited by R. Edwards, S. Sieminski, and D. Zeldin, 176-186. London: Routledge.

Edwards, P. 2010. A Vast Machine: Computer Models, Climate Data, and the Politics of Global Warming. Cambridge, MA: MIT Press.

Edwards, R., and P. Carmichael. 2012. "Secret Codes: The Hidden Curriculum of the Semantic Web." Discourse 33 (4): 575-590.

Edwards, P., S. Jackson, M. Chalmers, G. Bowker, C. Borgman, D. Ribes, M. Burton, and S. Calvert. 2013. Knowledge Infrastructures: Intellectual Frameworks and Research Challenges. Ann Arbor, MI: Deep Blue.

Evans, T., and D. Nation. 1992. "Theorizing Open and Distance Education." Open Learning 7 (2): 3-13.

Field, J. 1996. "Open Learning and Consumer Culture." In The Learning Society: Challenges and Trends, edited by P. Raggatt, R. Edwards, and N. Small, 136149. London: Routledge.

Halford, S., C. Pope, and M. Weal. 2012. "Digital Futures? Sociological Challenges and Opportunities in the Emergent Semantic Web." Sociology 47 (1): 173-189.

Kitchin, R., and M. Dodge. 2011. Code/Space: Software and Everyday Life. Cambridge, MA: MIT Press.

Knox, J. 2013. "Five Critiques of the Open Educational Resources Movement." Teaching in Higher Education 18 (8): 821-832.

Lampland, M., and S. Star. (Eds.) 2009. Standards and Their Stories: How Quantifying, Classifying, And Formalizing Practices Shape Everyday Life. Ithaca, NY: Cornell University Press.

Lewis, R. 1993. "What Is Open Learning?” In Key Issues in Open Learning: A Reader, edited by A. Tait. Harlow: Longman.

Loveless, A., and B. Williamson. 2013. Learning Identities in a Digital Age: Rethinking Creativity, Education and Technology. London: Routledge.

Manovich, L. 2013. Software Takes Command: Extending The Language of New Media. London: Bloomsbury Academic.

Millerand, F., and G. Bowker. 2009. "Metadata Standards: Trajectories and Enactment in the Life of An Ontology." In Standards And Their Stories: How Quantifying, Classifying, And Normalizing Practices Shape Everyday Life, edited by M. Lampland and S. Star, 149-176. Ithaca, NY: Cornell University Press. 
Natter, W., and J. Jones. 1997. "Identity, Space and Other Uncertainties.” In Space and Social Theory: Interpreting Modernity and Postmodernity, edited by G. Benko and U. Strohmayer, 141-161. Oxford: Basil Blackwell.

Panke, S., and T. Seufert. 2013. "What's Educational About Open Educational Resources? Different Theoretical Lenses for Conceptualizing Learning with OER." E-Learning and Digital Media 10 (2): 116-134.

Paul, R. 1993. "Open Universities - A Test of All Models." In Distance Education: New Perspectives, edited by K. Harry, M. Johns, and D. Keegan. London: Routledge.

Randall, D., R. Proctor, Y. Lin, M. Poschen, W. Sharrock, and R. Stevens. 2011. "Distributed Ontology Building As A Practical Work." International Journal of Human-Computer Studies 69 (4): 220-233.

Ribes, D., and G. Bowker. 2009. "Between Meaning And Machine: Learning To Represent The Knowledge of Communities." Information and Organization 19 (4): 199-217.

Stronach, I., and M. MacLure. 1997. Education Research Undone: The Postmodern Embrace. Maidenhead: Open University Press.

Thrift, N. 2004. "Remembering the Technological Unconscious by Foregrounding Knowledges of Position." Environment and Planning D: Society and Space 22 (1): 75-190.

Usher, R., and R. Edwards. 1994. Postmodernism and Education. London: Routledge. 